\title{
Capitalismo y violencia. A 150 años del libro I de El capital
}

\section{LUIS ARIZMENDI*}

Debido a que atravesamos por una crisis epocal, la más grave en la historia del capitalismo, la pregunta por la pertinencia de la obra cimera de Karl Marx, El capital, a 150 años de publicado el libro primero, concita a reconocer el influjo del poder planetario donde la subsunción formal y real del trabajo por el capital conforma la plataforma estructural de la guerra civil moderna. De tal suerte que el siglo xx puede ser representado como el siglo de la barbarie y en el primer tramo del siglo que transcurre es posible advertir el horror y la catástrofe precedentes. El capital es un libro fundacional que abre un horizonte original de comprensión crítica y cobra vigencia para descifrar la dialéctica entre capitalismo y violencia en la crisis epocal, además entraña un horizonte libertario ineludible para el siglo XXI.

* Profesor

investigador del Instituto Politécnico Nacional, México

\section{La vigencia de El capital entre las crisis cíclicas y la crisis epocal del capitalismo}

A 150 años de la publicación del libro I, hablar hoy de El capital no puede hacerse consistentemente al margen de la historia del poder planetario: sería improcedente pretender hacerlo guardando silencio sobre Auschwitz e Hiroshima. Indagar la vigencia de El capital convoca a reconocer al siglo XX como el Siglo de la Barbarie. Más aún, convoca a reconocer que el siglo XXI ha comenzado sin aprender del horror y la catástrofe del siglo anterior.

Cruzamos por la crisis más grave en la historia del capitalismo. Ni la Larga Depresión del siglo XIX (1873-1896) ni la Gran Depresión del siglo XX (1929-1944) conllevaron los peligros y las amenazas de la crisis de las civilizaciones que, a su vez, trae consigo la crisis epocal del capitalismo del siglo XXI. ${ }^{1}$

${ }^{1}$ Por caminos diferentes pero con coincidencias relevantes sobre la convergencia entre la crisis económica y la crisis ecológica, John Bellamy Foster, en 2013, también empezó a usar el concepto epochal crisis. Partió del modo en que Jason Moore emplea el concepto en 2011 para definir un largo periodo de transición del feudalismo al capitalismo, una época con complejas manifestaciones económicas, ambientales y sociales, que va de fines del medioevo hasta el siglo XVII. Bellamy Foster actualiza el concepto para caracterizar la gran crisis en la que estamos insertos sin que signifique el tránsito ineludible a un sistema histórico mejor. Desde mi contribución a la crítica de la mundialización capitalista en clave de valor de uso, inicié un desarrollo por cuenta propia, que comencé a publicar en 2009, con el concepto de crisis epocal del capitalismo. Véase John Bellamy Foster, «The epochal crisis», Monthly Review, vol. 65, núm. 5, 2013, en https://monthlyreview.org/2013/10/01/ 
Al conformar la primera crisis de sobreproducción propiamente planetaria - la crisis de sobreproducción de la Larga Depresión fue europea y la de la Gran Depresión fue intercontinental y afectó en particular a Estados Unidos, Europa y Japón - , la gran crisis de sobreacumulación del nuevo siglo comenzó su explosión de modo simultáneo con el estallido de una profunda crisis financiera global. ${ }^{2}$ Sin embargo, ni siquiera juntas, la crisis de sobreproducción y la crisis de sobrefinanciamiento globales, abarcan los peligros de la crisis contemporánea en todos sus alcances. Si se le escudriña en clave de valor de uso, es decir, desde la vida humana como fundamento para la crítica de la modernidad capitalista, emergen la mundialización de la pobreza (que no era planetaria, pero el «neoliberalismo» volvió la pobreza una desestabilización global en la vuelta de siglo), la crisis alimentaria mundial (resultado de la radicalización de los impactos de la pobreza extrema) y la crisis ambiental mundializada (que se apuntala sobremanera con la salida de Estados Unidos de los Acuerdos de París) como los tres peligros seculares más radicales contenidos en la crisis epocal del capitalismo del siglo XXI.

Cuando Bradford DeLong ${ }^{3}$ califica la crisis global contemporánea como Segunda Gran Depresión, si bien positivamente se aproxima a identificarla como una gran crisis (olvida la Larga Depresión del siglo XIX y obstruye la pe-

epochal-crisis/; Jason Moore, «Transforming the metabolic rift: a theory of crises in the capitalist world ecology», Journal of Peasant Studies, vol. 38, núm. 1, 2011, en http://www. tandfonline.com/doi/full/10.1080/03066150.2010.538579; Luis Arizmendi, «La especificidad histórica de la crisis mundial contemporánea», Mundo Siglo XXI, núm. 17, 2011, en http:// www.mundosigloxxi.ipn.mx/pdf/v05/17/03.pdf

${ }^{2}$ Elmar Altvater, «Un análisis crítico de la crisis financiera global. ¿Marx tenía razón después de todo?», Mundo Siglo XXI, núm. 20, 2010, en http://www.mundosigloxxi. ipn.mx/pdf/v05/20/01.pdf

${ }^{3}$ Bradford DeLong, «The Second Great Depression», Foreign Affairs, julio-agosto, 2013, en http://www.foreignaffairs. com/articles/139464/j-bradford-delong/the-second-great -depression riodización precisa de las grandes crisis en la historia del capitalismo), resulta una caracterización conceptualmente insuficiente para descifrar la magnitud histórica de los inéditos peligros en curso.

Si ya del entrecruzamiento de la crisis alimentaria global con la crisis ambiental mundializada surge el peligro de la potencial transición de una escasez espuria o artificial (basada en el monopolio especulativo de la economía alimentaria internacional) hacia una escasez absoluta de alimentos (derivado de la devastación creciente de cultivos agrícolas conforme avanza la marcha del sobrecalentamiento planetario a lo largo del siglo), y si al revisar los modelos estadísticos con desenlaces antinómicos se indaga la secular trend de la crisis ambiental mundializada para descubrir que despliega una dinámica sumamente destructiva que apunta hacia una devastación equivalente a una guerra atómica planetaria (posible a partir de la liberación de las grandes reservas de metano contenidas no sólo en el permafrost siberiano, sino en el fondo de los océanos), ${ }^{4}$ entonces el panorama de lo que significa la crisis epocal se redondea cuando se incorpora, junto a los dos peligros mayores anteriores, la geopolítica nuclear del nuevo siglo.

Aunque la Gran Depresión del siglo XX es incomprensible sin la Segunda Guerra Mundial - porque la devastación opera como una necesidad estructural profunda de la acumulación capitalista en tanto se relanza a sí misma a partir de aprovechar económicamente el carácter imperioso de la enorme reconstrucción ulterior-, el peligro del estallido de un conflicto bélico a gran escala o incluso de una Tercera Guerra Mundial como posible desenlace de la actual crisis de sobreproducción planetaria representa una amenaza superior al doble de Auschwitz e Hiroshima.

\footnotetext{
${ }^{4}$ Luis Arizmendi, El capital ante la crisis epocal del capitalismo, México, Instituto Politécnico Nacional, 2016, pp. 141-147.
} 
A pesar de que la perspectiva de Piketty choca duramente con las ilusiones meritocráticas del «neoliberalismo» (según lo cual el laissez faire, laissez passer abre camino a cada individuo en tanto desarrolla sus capacidades), su intervención está construida para otorgarle una nueva versión al mito del progreso. Cuando el enriquecimiento del 1 por ciento más rico de la población mundial es escandalosamente inocultable, la versión de Piketty acerca de la historia de la desigualdad a escala mundial - junto con información estadística que demuestra cómo la brecha abierta en el siglo XIX se fue cerrando en el curso del siglo XX para volverse a abrir con mayor magnitud, pero ahora a escala mundial en la transición al siglo XXI - insiste en la ilusión de que la modernidad capitalista representa la viabilidad del progreso económico universalizable y del progreso político democrático si se aplican y desarrollan las políticas correctas. Su perspectiva acerca del diseño de políticas económicas y públicas capaces de aprovechar las oportunidades de la revolución informática en el nuevo siglo intenta hacer manejables los impactos destructivos de esta revolución tecnológica a fin de dotar de un mayor marco de acción a la administración estratégica de la lucha de clases mundializada. ${ }^{6}$ En ese sentido, el libro de Thomas Piketty representa la negación desde el liberalismo contemporáneo de una crítica de la economía política del siglo XXI.

Desde una óptica neoautoritaria, diferente a la de Piketty, incluso la British Broadcasting Corporation (BBC) de Londres, como fuerza estratégica del cuarto poder mundializado, ha hablado de la vigencia de Karl Marx «a pesar del fracaso del comunismo»; no obstante, es sumamente notorio que su reconocimiento del carácter cíclico o invariablemente recurrente de las crisis económicas del capitalismo, en el contexto de lo que califica como un «colapso financiero nunca antes visto», ${ }^{7}$ está inserto en el intento por invisibilizar lo inocultable. El discurso unidimensional — para construir una expresión que evoque El hombre unidimensional de Herbert Marcuse como

${ }^{6}$ Thomas Piketty, El capital en el siglo XXI, México, Fondo de Cultura Económica, 2014.

${ }^{7}$ British Broadcasting Corporation (BBC), «4 ideas de Carlos Marx, el ideólogo de la Revolución rusa, que siguen vigentes a pesar del fracaso del comunismo», 2017, en http://www.bbc.com/mundo/noticias-40611669

\section{Cruzamos por la crisis más grave en la historia del capitalismo, en la que emergen tres peligros seculares: la mundialización de la pobreza, la crisis alimentaria global y la crisis ambientat.}
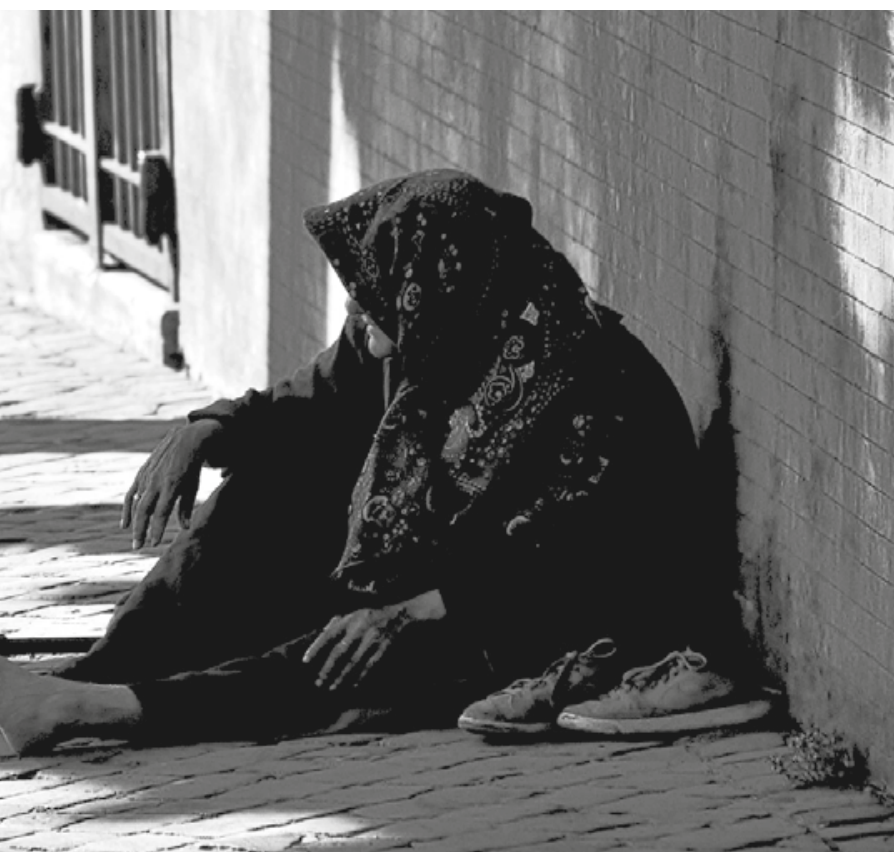
crítica a la modernidad atómica — ${ }^{8}$ insiste en reducir la crisis epocal a crisis financiera y desigualdad social globalizadas porque apunta a invisibilizar mediáticamente la secular trend de la crisis ambiental mundializada y de la crisis alimentaria global. No sólo porque responde a su posición al insertarse y propulsar la geopolítica bélica y nuclear del siglo XXI, para la BBC los riesgos de guerra a gran escala provienen no de la disputa por la hegemonía global, sino de las «amenazas a la democracia», externas a la modernidad capitalista, que representan regímenes como los de Corea del Norte o Venezuela. En otras palabras, lee la vigencia de El capital pero mutilándola unidimensionalmente en función de sus profundos servicios para la «máquina de la desimaginación» planetaria, ${ }^{9}$ es decir, para el ocultamiento mediático de los fundamentos de la disputa por la hegemonía mundial y la marcha del binomio capitalismo/barbarie en el siglo XXI. Se desconoce el binomio inextricable capitalismo/barbarie en el momento en que se le propulsa históricamente. En la actual ofensiva geopolítica de la ultraderecha contra Venezuela, la BBC ha cumplido un papel clave.

Resulta revelador que no sólo la tendencia liberal sino también la tendencia neoautoritaria están impelidas a reconocer la vigencia de la magnum opus de Marx en nuestra era. La disputa entre la tendencia que aboga por un capitalismo propiamente liberal (con el sistema de Estados como contrapeso ante la destructividad del capitalismo contemporáneo) y la tendencia neoautoritaria (que agrega la violencia político-destructiva del Estado a la violencia económico-anónima del «libre juego de las fuerzas del mercado» del capitalismo de la vuelta de siglo), se decanta a favor de la segunda.

\footnotetext{
${ }^{8}$ Herbert Marcuse, El hombre unidimensional, México, Joaquín Mortiz, 1984.

${ }^{9}$ Henry Giroux, «Más allá de la máquina de la desimaginación», Mundo Siglo XXI, núm. 31, 2013, en http://www. mundosigloxxi.ipn.mx/pdf/v09/31/04.pdf
}

Leer El capital hoy para integrarlo a nuevas versiones del mito del progreso o, peor aún, a lecturas unidimensionales dirigidas a justificar el binomio capitalismo/barbarie, obstruye el relanzamiento del marxismo crítico ante el desafío que significa descifrar la crisis epocal del capitalismo en todos sus alcances. Como se aprecia, El capital de Marx está de regreso en el debate internacional.

\section{La reconceptualización de la «guerra civil» y su tendencia epocal}

En un agudo ensayo de título irónico, «El sentido del siglo XX», que da cuenta del sinsentido radical del Siglo de la Barbarie o el Siglo de las Tinieblas, como le gustaba decir, Bolívar Echeverría introdujo una insólita redefinición del concepto «guerra civil», a partir de desarrollar el complejo significado que Marx le adjudicó en El 18 brumario de Luis Bonaparte. ${ }^{10}$

$\mathrm{Al}$ ampliarlo para rebasar el significado regular del término «guerra civil» — que nombra el enfrentamiento violento de dos proyectos de nación al interior de un mismo Estado o de dos proyectos de Estado al interior de una misma nación-, Bolívar Echeverría puso énfasis en que el capitalismo constituye un sistema histórico permanentemente violento y que de ninguna manera la guerra civil conforma dentro de él una desestabilización puramente temporal o pasajera. Lo anterior porque de modo singular en la historia de las sociedades de clase ha hecho del estado de pax, es decir, de un simulacro de paz o de falso alto al fuego, una situación estructural de la economía moderna.

Parafraseando a Clausewitz, podríamos decir que la modernidad capitalista ha hecho de la economía la continuación de la guerra por otros medios. En ese proceso histórico, precisamente, la subsunción formal y la subsunción real del trabajo por el capital constituyen

\footnotetext{
${ }^{10}$ Bolívar Echeverría, Vuelta de siglo, México, Era, 2006.
} 
la plataforma estructural de la guerra civil moderna.

La subsunción formal del trabajo por el capital — que, luego de que constituye la primera gran fase del desarrollo capitalista, se integra como la base permanente de la relación global del capitalismo - funda un estado de violencia histórica sumamente singular. Una configuración única de la violencia en la historia de las sociedades de clase: integra la violencia económico-anónima como fundamento permanente del capitalismo.

En profundo contraste con la violencia visible propia de la esclavitud antigua o del despotismo asiático, la subsunción formal plasma en la estructura inercial de la economía moderna una violencia «invisible» pero efectiva y radical. La expropiación de medios de vida - lo que significa que la expropiación de medios de producción impone invariablemente una segunda expropiación, es decir, que sobre ella genera la expropiación de medios de consumo - instala una crisis de orden estructural, una auténtica situación límite contra el proceso de reproducción vital de los dominados modernos. Colocados en un ineludible estado de peligro, sin medios de vida para los dominados modernos, el riesgo de muerte, la certidumbre sobre la incertidumbre vital, se torna el fundamento de la violencia económico-anónima en el capitalismo. Un simulacro de paz se vuelve la regla. ${ }^{11}$

$\mathrm{Al}$ pretender volver vivible lo invivible, lo que comenzó siendo una violencia exterior es interiorizada por los dominados modernos. En el momento en que admiten como normal la anormal mercantificación de su fuerza laboral, un peculiar entrecruzamiento se pone en acto: la estrategia espontánea de sobrevivencia, respondiendo a la búsqueda por abrirse acceso a los medios de consumo, se vuelve la vía inocultable de integración al dominio

${ }^{11}$ Bolívar Echeverría, Las ilusiones de la modernidad, México, Universidad Nacional Autónoma de México/El Equilibrista, 1995. establecido. Cuando se logra la sedimentación histórica de esa estrategia, conformándose como costumbre, esto es, como comportamiento cotidiano, automático e irreflexivo se constituye, bajo una u otra forma histórica, lo que profundamente Bolívar Echeverría denominó ethos moderno. ${ }^{12}$

Cuando se transita a la subsunción real del trabajo por el capital como segunda gran fase del desarrollo capitalista — sin que jamás desaparezca la subsunción formal como base permanente de la dominación moderna - , la violencia económico-anónima se vuelve aún más ofensiva. Trayendo al mundo la modernidad pero bajo su dominio, el capitalismo codifica o plasma la legalidad de su poder en la estructura material de la tecnología automatizada. Hace de la revolución tecnológica y del general intellect un arma integrada a la legalidad opresiva de la subsunción real.

Siendo enteramente viables y factibles otras trayectorias de automatización e innovación tecnológica, que podrían dirigirse hacia la afirmación del mundo humano de la vida, el capital sabotea y bloquea, una y otra vez, esas potencialidades para imponer en su lugar trayectorias cada vez más violentas de modernización tecnológica funcionales al apuntalamiento creciente de su poder económico y su poder planetario.

En ese sentido, la expresión ejército industrial de reserva de ningún modo debe leerse como una simple alegoría. No se trata del traslado puramente metafórico por Marx de un término proveniente del argot militar al pensamiento económico moderno. Representa un concepto duro dirigido en específico

\footnotetext{
${ }^{12} \mathrm{Al}$ desarrollar de manera muy original la caracterización de las diversas formas de complicidad e integración con el dominio establecido a partir de las estrategias de sobrevivencia contemporáneas, Echeverría edificó su conceptualización del cuádruple ethe de la modernidad capitalista (como ethos realista, romántico, clásico y barroco). Véase Bolívar Echeverría, Modernidad, mestizaje cultural, ethos barroco, México, Universidad Nacional Autónoma de México/El Equilibrista, 1994.
} 
a desocultar el profundo carácter de guerra civil inmanente a la subsunción real capitalista de la modernización tecnológica. Es un concepto que denuncia cómo en la medida en que el poder productivo de la técnica planetaria subsumido realmente por el capital es llevado cada vez más lejos. La modernidad capitalista devasta en una escala mayor el proceso de reproducción social y produce ascendentemente heridos y muertos. La economía moderna, así, se vuelve el campo de una guerra civil clasista, anónima o impersonal, pero tendencialmente cada vez más peligrosa.

La Ley General de la Acumulación Capitalista — más allá de ser una ley enclaustrada en el siglo XIX, como tanto insiste desfigurándola el reduccionismo del marxismo progresista-, constituye una ley, justo y ante todo, porque da cuenta de una tendencia epocal. Demuestra que la mundialización capitalista es una modernidad esquizoide, precisamente, porque para apuntalar su poder planetario el capitalismo entrecruza, cada vez más profunda y amenazadoramente, progreso $y$ devastación.
En la medida en que el capitalismo hace uso y abuso de la revolución tecnológica como arma, instala un doble impacto sobre los dominados modernos: impone tasas internacionales de explotación cada vez más altas, pero además de traicionar las potencialidades positivas de la modernidad, conduce el progreso tecnológico por trayectorias esquizoides que despliegan una devastación cada vez más destructiva desde la violencia económico-anónima inmanente a la acumulación planetaria.

$\mathrm{Al}$ ser esta la ley que rige la marcha de la mundialización capitalista, cada Estado y cada fase de la historia contemporánea poseen un marco de acción, delimitado pero efectivo, para concederle una u otra configuración histórica a la modernidad. El capitalismo no es homogéneo ni a lo ancho del orbe ni a lo largo de su devenir. Adquiere una de las diversas configuraciones posibles para hacer más administrable o más radical la dialéctica permanente entre violencia y capitalismo.

Al observar panorámicamente el abanico de configuraciones factibles de la modernidad y la mundialización capitalistas basadas en la
En profundo contraste con la violencia visible propia de la esclavitud antigua, la subsunción formal plasma en la estructura inercial de la economía moderna una violencia «invisible» pero efectiva y radical.

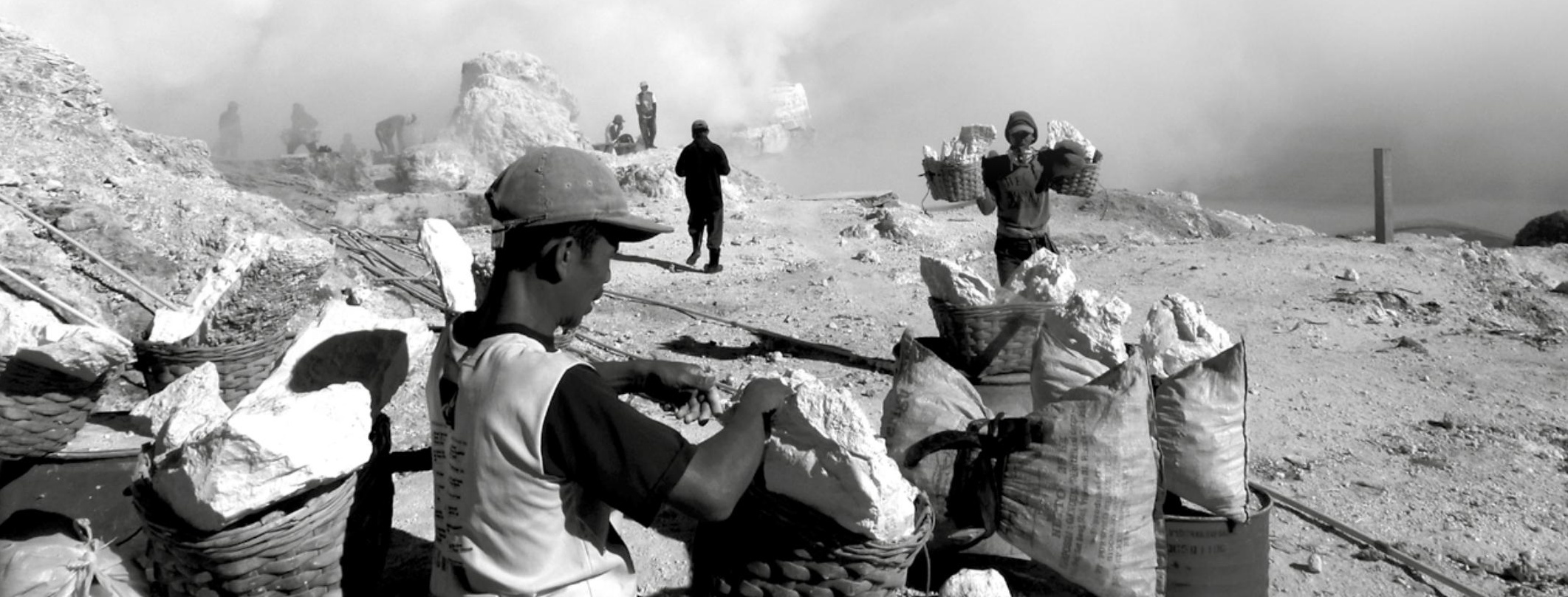


subsunción real — después de siglo y medio de historia del poder planetario a partir de la publicación del libro I de El capital - podría afirmarse que, según los requerimientos de los ciclos y las fases de la acumulación, así como de la disputa por la hegemonía mundial, que se concretan de acuerdo con la rapport de forces de la lucha nacional, internacional y mundializada de clases, el capitalismo y sus Estados despliegan una de tres configuraciones históricas posibles .

Capitalismo liberal es el nombre que - siguiendo el uso regular que las ciencias históricas le asignan al término liberalismo - cabe asignar a aquella configuración que se conforma cuando se hace efectivo que el Estado intervenga como contrapeso ante la violencia económico-anónima inmanente a la acumulación. En el siglo XX, las políticas para elevar el estándar de vida social, el ejercicio regular de procesos electorales y la promoción de la soberanía nacional fueron los ejes que caracterizaron a la modernidad liberal. En el siglo XXI se busca revertir la ofensiva del mal denominado «neoliberalismo», el capitalismo genuinamente liberal, además ha lanzado propuestas sobre reducción de la pobreza, del hambre global y la transición a un patrón energético pospetrolero.

Capitalismo cínico — parecido a lo que Armando Bartra denomina «capitalismo canalla» - es el nombre que procede atribuirle a una configuración que sin anular jamás la intervención del Estado en la economía, la hace valer para garantizar el traslado del centro de mando hacia el capital privado, ante todo hacia el capital privado transnacional. Laissez faire, laissez passer o «libre juego de las fuerzas del mercado» no significa otra cosa que libre ejercicio y despliegue irrestricto de la violencia económico-anónima como arma de los capitales privados. Por la ineludible inestabilidad que introduce en la administración estratégica de la acumulación y la lucha nacional y mundializada de clases, esta configuración incuba la promoción del tránsito hacia otra modalidad invariablemente más violenta del capitalismo.

Capitalismo autoritario - siguiendo el concepto de Estado autoritario formulado por Horkheimer - ${ }^{13}$ es la configuración histórica que no se detiene en imponer el entrecruzamiento creciente, cada vez más amenazador, de violencia económico-anónima y violencia político-destructiva como medio imperioso para contrarrestar las inestabilidades económico-políticas del capitalismo y apuntalar su poder. Esta es la configuración a la que tiende el capitalismo histórico en tiempos de crisis y que rebasa a la configuración cínica.

Cuando aparte del Estado los capitales privados despliegan una violencia político-destructiva, la configuración de la propulsión a la barbarie en la modernidad capitalista se redondea en el momento en que es interiorizada por los dominados modernos. Si esa tragedia se abre paso entre ellos, nunca es sólo

${ }^{13}$ Max Horkheimer, Estado autoritario, México, Ítaca, 2006. 
porque estén engañados y actúen contra sus necesidades históricas.

Asumir que la promesa del progreso económico para todos es cosa del pasado, pero que el conforty la opulencia únicamente podrán existir para unos cuantos, más que la exclusión, se admite e incluso se propulsa la destrucción de muchos más. De esa forma se puede garantizar el acceso a una riqueza que jamás será universalizable: es la elección histórica que conduce a la complicidad de los dominados modernos con el binomio inextricable capitalismo/ barbarie.

En el siglo XX, el nazismo y el fascismo le dieron forma al capitalismo autoritario y esta complicidad proviene de la radicalización decadente del ethos realista moderno. En el siglo XXI, una tendencia neoautoritaria (con un alcance transcontinental, desde Estados Unidos y Europa) se ha estado imponiendo históricamente.

Al revisar, desde la Ley General de la Acumulación Capitalista como fundamento de la guerra civil moderna, una formulación tan aguda e iconoclasta como la planteada por Walter Benjamin, cuando afirmó que el Estado de excepción se había vuelto la regla, ${ }^{14}$ se revela que su horizonte crítico sobre la historia política de nuestra era debe ser leído ante todo como una advertencia para el porvenir. Si la tendencia epocal de la acumulación planetaria, desde la revolución tecnológica como arma, propulsa una guerra civil clasista cada vez más radical, la tendencia epocal de la mundialización capitalista propulsa la propagación del Estado de excepción como medio ineluctable para el manejo de una guerra civil capitalistamente cada vez más violenta.

Leído así el libro I de El capital es identificable como el texto fundacional de un horizonte insólito de intelección crítica de inapelable ac-

${ }^{14}$ Walter Benjamin, Tesis de filosofía de la historia, México, Ítaca, 2008; Giorgio Agamben, Estado de excepción: homo sader II, España, Pre-Textos, 2004. tualidad para descifrar la tendencia epocal de la dialéctica permanente entre capitalismo y violencia.

\section{El horizonte libertario de El capital en el siglo XXI}

En el marco de la crisis epocal del capitalismo, insistir en leer El capital desde la perspectiva del marxismo progresista (ya fuera en su versión de marxismo socialdemócrata o en su versión de «marxismo soviético»), representaría un gran obstáculo. El tiempo de peligro que el siglo XXI trae consigo con la crisis de mayores amenazas en la historia del capitalismo planetario invita a releer El capital a partir de asumir propiamente como principio heurístico redescubrir a Marx, para expresarlo evocando el título de la obra más reciente de Elmar Altvater. ${ }^{15}$

No sólo la crisis epocal convoca al desarrollo de frontera de la crítica al capitalismo del siglo XXI en clave de la contradicción valor/valor de uso, es decir, desde el complejo choque del proceso de reproducción de la vida de la sociedad planetaria y la acumulación mundial del capital, además convoca a redescubrir El capital releyéndolo en clave de valor de uso.

Las luchas contrahegemónicas y transcapitalistas contra la mundialización de la pobreza, la crisis alimentaria global, la crisis ambiental mundializada, la geopolítica nuclear y el peligro de una Tercera Guerra Mundial, como configuración extremadamente amenazante de la fuerza de la Ley General de la Acumulación Capitalista en el siglo XXI, requieren complejos desarrollos de la crítica de la economía política en clave de valor de uso. Nunca como ahora la «forma social-natural» de la reproducción humana ha mostrado tanta actualidad en su vigencia como fundamento de la racionalidad crítica.

\footnotetext{
${ }^{15}$ Elmar Altvater, Redescubrir a Marx, México, Fundación Rosa Luxemburgo,2017.
} 
De ningún modo el reconocimiento de la Ley General de la Acumulación como tendencia epocal de la mundialización capitalista es sinónimo de reducción del porvenir a una especie de destino ineluctable. Desde Rosa Luxemburgo, el marxismo crítico dejó claro que la crítica irrenunciable a la encrucijada socialismo o barbarie impugna contundentemente asumir al socialismo como destino, pero también a la barbarie.

Si la autogestión o la autodeterminación política es identificada como el principio estratégico general, imprescindible para avanzar en la edificación de una modernidad alternativa frente y contra la legalidad esquizoide de la modernidad capitalista $-\mathrm{y}$, sin duda, en eso reside el horizonte libertario global de El capital-, emergen cuatro retos históricos de primer orden en el siglo XXI.

1) Impulsar la liberación del proceso de reproducción social-nacional de la subsunción real bajo la Ley General de la Acumulación Capitalista conlleva el complejo y alto desafío de integrar la autogestión como fundamento creciente de la organización económico-política en espacios locales delimitados, fomentar su multiplicación y explorar el mayor abanico posible de alianzas plurales que permitan abrir paso - para decirlo en léxico luxemburguiano - hacia el «autogobierno del país». En este sentido, la lucha por la autogestión y la soberanía nacional requerirían superar su antinomia histórica regular para ser reinventadas como dimensiones imprescindibles y vitales en la edificación de una modernidad alternativa.

2) La lucha contra la mundialización de la pobreza y la crisis alimentaria global - la peor crisis alimentaria en la historia de la humanidadreclama avanzar hacia la conquista de derechos inéditos de desmercantificación del proceso de reproducción social. Si la economía mundial ali- $\quad \ldots$ mentaria cuenta con la capacidad productiva para proveer de víveres al doble de la sociedad planetaria, es política y moralmente inadmisible el hambre y su propagación. Porque la potencialidad de la abundancia proyecta la viabilidad de
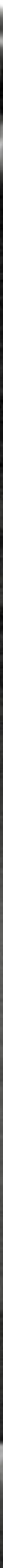
